\title{
Determination of the antioxidant additive "lonol" in transformer oil by gas chromatographic method
}

\author{
Nguyen Duy Hung ${ }^{1, *}$, A.V. Taneva ${ }^{1}$, and V.F. Novikov ${ }^{1}$ \\ ${ }^{1}$ Kazan State Power Engineering University, Kazan, Russia \\ ${ }^{2}$ Viet - Hung Industrial University, Ha Noi, Viet Nam
}

\begin{abstract}
Transformer oil is widely used in power oil-filled electrical equipment, which is an insulating and diagnostic medium. During the operation of power transformers, its operational and dielectric properties deteriorate. To increase the operating time of transformer oil, it is inhibited by an antioxidant additive, which is most often used as ionol and the ionol concentration must be constantly monitored. This control is carried out by chromatographic methods. The main problem of controlling the antioxidant additive in transformer oil is its extraction with organic extractants, which are ethyl alcohol, which contains water, which has a negative effect on the extraction process. Thus, a search for more effective extractants for the extraction of ionol from transformer oil was undertaken. The retention characteristics of individual organic extractants and antioxidant additives were determined by the method of high-performance gas-liquid chromatography using a quartz capillary column and an automated system for dosing a sample into the chromatograph under various experimental conditions. Both the isothermal mode of the experiment and under linear programming conditions of the chromatographic column have been used. The dependence of the retention characteristics of organic extractants and ionol on the temperature of analysis was established, which has a linear form.
\end{abstract}

\section{Introduction}

To extend the service life of transformer oil, an antioxidant additive is introduced into it, which is most often used as 2.6-di-tertiary butyl vapor - cresol under the brand name "Ionol". The mechanism of action of this additive lies in its ability to interact with active radicals, which are formed as a result of a chain reaction of oxidation of transformer oil. In this case, a more stable molecule is formed, which is less susceptible to the oxidation process [1-3]. To control the stability of transformer oil and its resistance to oxidation, various instrumental methods of analysis are used, with the help of which it is possible to determine the dielectric losses, as well as some electrical properties [4-5]. The process of oxidation of transformer oil can also be slowed down by introducing hydrocarbons with phenyl radicals into the composition of transformer oil [6-7]. Typically, an antioxidant additive is added to transformer oil at the manufacturing stage. In this case, the additive should dissolve well in the transformer oil at room temperature [8]. During the operation of transformer oil, an antioxidant additive dissolved in the oil is produced. In this case oxidation products are formed, which lead to a deterioration in the operational properties of the transformer oil and its rapid aging [9-10]. Oxidation of transformer oil leads to accelerated destruction of paper insulation, which is associated with the weakening of glucose bonds. This promotes oxidative depolymerization. The process of decomposition of organic substances contained in transformer oil [11-12].

Usually in fresh transformer oils inhibited by ionol, in addition to hydrocarbon components, the content also contains iron, copper, magnesium, naphthenic, calcium salts of naphthenic and sulfonic acids, which are degradation products and are accompanied by a decrease in the dielectric strength of the oil [13-14]. Based on the foregoing, it is necessary to constantly monitor the content of the antioxidant additive, since it is produced and in the presence of ultraviolet radiation it can decompose [15].

The antioxidant additives are controlled using gasliquid chromatography. Methodological guidelines have been developed, which are based on the analysis of Ionol using packed chromatographic columns filled with a weakly polar stationary phase XE-60. More promising is the use of a highly selective stationary phase, prepared on the basis of triphenyl derivatives of the fifth group of the periodic table [16], or the use of arsenated polyethylene glycols, which show high selectivity for the separation of hydroxyl compounds due to the presence of a stationary electron pair of arsenyl oxygen [17-18].

In the chromatographic control of the antioxidant additive in transformer oil, the sample preparation procedure is of great importance. Usually, Ionol is extracted from transformer oil with ethyl alcohol, which contains a significant amount of water. In the works of Korobeinikov S.M. it is shown that an increase in the

* Corresponding author: hungnguyenat73@gmail.com 
water content in ethyl alcohol leads to a deterioration in the extraction process and when water is contained in an amount of up to $15 \%$, the amount of the additive extracted from the transformer oil is more than $60 \%$ of the mass [19]. The determination of the antioxidant additive in transformer oil by chromatographic methods is described in detail in the monograph [20].

\section{Materials and methods}

The experimental part of the work was carried out on a certified gas-liquid chromatograph "Chromos GH1000", with a flame ionization detector, a quartz capillary column $30 \mathrm{~m}$ long, $0.32 \mathrm{ml}$ inner diameter. The capillary column is filled with a stationary phase based on Vako BoHa VB WAX P/n polyethylene glycol, with a film thickness of $0.5 \mu \mathrm{m}$. Argon was used as the carrier gas, the rate of which, when passing through the capillary column, was $0.85 \mathrm{ml} / \mathrm{min}$. The detection of the separated components results using a flame ionization detector with a level of fluctuation noise of the zero signal no more than $1 * 10^{-14} \mathrm{~A}$, with a detection limit for heptane in nonane $2.0^{*} 10^{-14} \mathrm{~g} / \mathrm{s}$. The hydrogen flow rate for powering the detector was $25 \mathrm{ml} / \mathrm{min}$, air 250 $\mathrm{ml} / \mathrm{min}$. The dosage of the sample of organic extractants and the antioxidant additive "Ionol" is carried out using an automatic liquid dispenser ALD-23, designed to inject up to twenty-three samples of the analyzed substances into the chromatograph evaporator. Organic substances of various physical and chemical nature were used as extractants. Evaluation of the selective characteristics of the systems under study was carried out on the basis of absolute retention times, on the basis of which the relative retention volume was calculated and the content is analyzed.

\section{Results and discussions}

The antioxidant additive "Ionol", added to transformer oil, is a hydrophobic compound and is readily soluble in aliphatic alcohols. The ethyl alcohol proposed for the extraction of ionol from transformer oil contains a large amount of water, so the extraction results are poorly reproducible. In addition, ethyl alcohol contains a significant amount of impurity compounds separation chromatogram which are shown in fig. 1.

In fig. 1. Shown is a chromatogram of the separation of impurity compounds in ethanol.

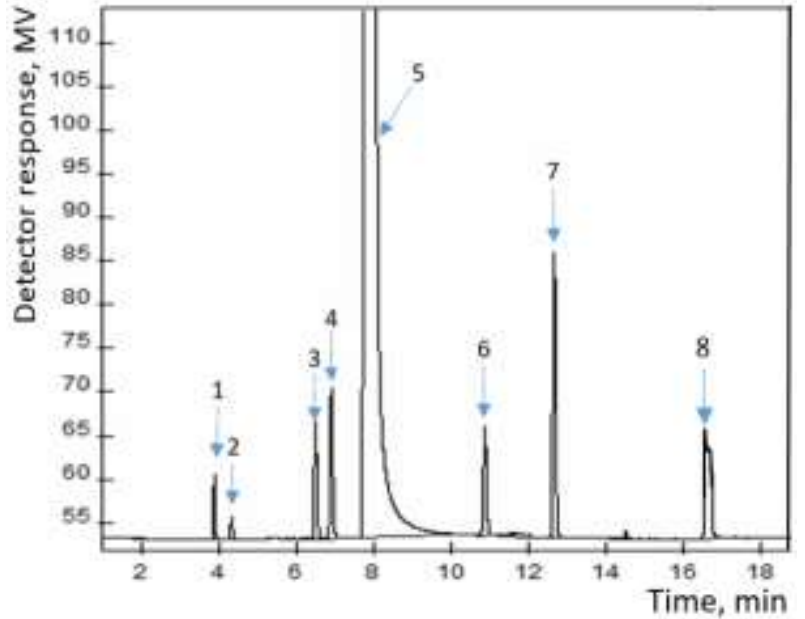

Fig. 1. Chromatogram of the separation of impurity compounds in ethanol.

Analysis conditions: Chromatograph brand "Chromos GH-1000", with flame ionization detector, capillary quartz column $30 \mathrm{~m}$ long, with an inner diameter of $0.32 \mathrm{~mm}$, filled Vako BoHa VB WAX P/n CF 5903032050A. Carrier gas velocity $0.85 \mathrm{ml} / \mathrm{min}$. Linear programming of the column temperature from $50^{\circ} \mathrm{C}$ up to $160^{\circ} \mathrm{C}$ with a temperature rise rate of five degrees per minute. Peaks on the chromator: 1 Acetaldehyde; 2 - Acetone; 3 - Ethyl acetate; 4 Methanol; 5 - Ethanol; 6 - iso.-Butanol; 7 - n.Butanol; 8 - iso.-Aminol.

In addition to water, ethyl alcohol also contains other organic compounds that can affect the extraction of ionol from transformer oil.

Table. 1 shows physicochemical and chromatographic properties of impurities in ethyl alcohol. Boiling point $\left(\mathrm{T}_{\text {Boiling }},{ }^{0} \mathrm{C}\right)$; Melting temperature ( $\mathrm{T}_{\text {Melting, }}{ }^{0} \mathrm{C}$ ); Efficiency per meter of capillary chromatographic column $\left(\mathrm{N}_{\mathrm{m}}\right)$; Asymmetry coefficient of chromatographic peaks $\left(\mathrm{C}_{\mathrm{A}}\right)$; Absolute retention time of the chromatographic peak ( $\mathrm{t}_{\text {retention. }}$ min.); Logarithm of the absolute retention time of the chromatographic peak (lgt retention. min.); Mass concentration of the analyzed substances (C,\% wt).

Table 1. Physicochemical and chromatographic properties of associated impurities in ethyl alcohol.

\begin{tabular}{|c|c|c|c|c|c|c|c|c|c|}
\hline Si, & Copsenti & Fomin & $\begin{array}{c}T_{3 e d} \\
{ }^{c} \mathrm{C}\end{array}$ & $\begin{array}{c}T_{\text {wea }} \\
{ }^{\prime} \mathrm{C}\end{array}$ & $\mathrm{N}_{a}$ & $c_{1}$ & $\begin{array}{l}\text { bas } \\
\text { mit }\end{array}$ & $\begin{array}{c}\text { Iglumat } \\
\text { min }\end{array}$ & $\begin{array}{l}\text { C. } 8 \\
\text { का }\end{array}$ \\
\hline 1 & Aomalitntyde & Cस्वा & 302 & -1225 & 833 & 26 & 3.73 & 0.57 & 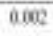 \\
\hline 2 & Slethovol & CHAOA & 6At & -970 & 35 & 24 & 6.22 & 65 & 0603 \\
\hline 3 & Flatal & C:BOA & 724 & -1141 & 405 & 0.2 & 783 & 695 & 95.779 \\
\hline 4 & so-buand & ICH:ZCACHOH & 1989 & -101.9 & 3280 & 1.2 & 11.34 & 195 & 0002 \\
\hline 3 & nhtumal & CHAOA & $117 A$ & -1141 & 5518 & 69 & 1280 & 1.11 & $0 \omega 0$ \\
\hline 6 & ise Aninal & (CHIECHKCOAO & 1310 & .1172 & $47 \%$ & of & $16+5$ & 121 & 000 \\
\hline 7 & Whiter & PBo & 1000 & 9 & + & - & 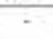 & 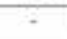 & 4214 \\
\hline
\end{tabular}

The ethyl alcohol content is $95.775 \%$ of the weght (table 1). At the same time, it contains water in the amount of $4.214 \%$ wt., which has a negative effect on the process of ionol extraction from transformer oil. As a rule, to remove water from ethanol, it is absolute or 
sorption methods of purification with the absorption of moisture by selective sorbents are used. In the conditions of testing laboratories of power enterprises, sample preparation of transformer oil by liquid extraction of ionol leads to a complication of the process due to the introduction of additional manual steps. Moreover, in the case of removing moisture from ethanol, it is necessary to constantly monitor this process at a quantitative level using precision equipment, which leads to unjustified economic costs. In addition, the presence of water in ethanol leads to an increase in the time to reach equilibrium distribution of components between the immiscible phases, which is difficult to control. The water present in ethanol promotes hydrolysis of the stationary liquid phase in the chromatographic column, shortens its operation time and ultimately disables it. Thus, ethanol contains a sufficiently large amount of impurity compounds, and water, which can directly affect the antioxidant additive, which is also present in a small amount in the transforming oil.

In fig. 2. The dependence of the logarithm of the retention time of the impurity components contained in ethanol on their boiling points is shown.

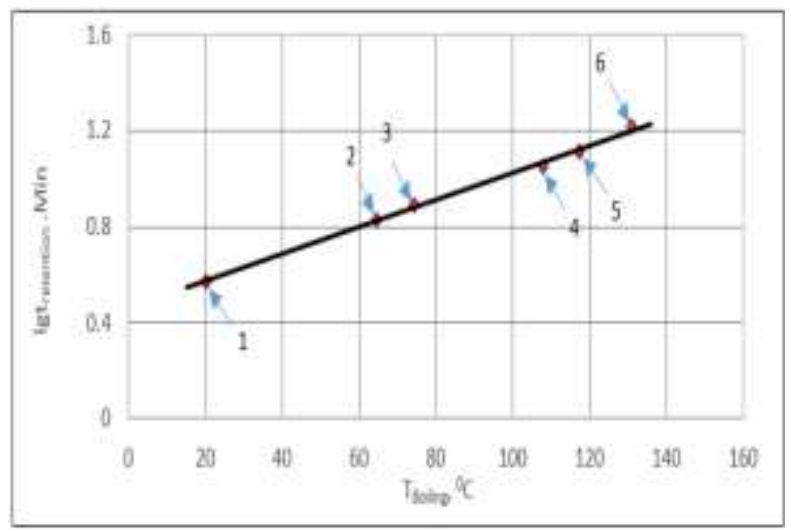

Fig. 2. Addiction logarithm of the retention time of the impurity components contained in ethanol from their boiling points (The experimental points correspond to the results shown in Table. 1). 1 - Acetaldehyde; 2 - Methanol; 3 Ethanol; 4 - iso.-Butanol; 5 -n.-Butanol; 6 -iso.-Aminol.

Fig. 2 shows for the components contained in ethyl alcohol, there is a linear dependence of the logarithm of the retention time of impurities on their boiling point, which does not contradict the main provisions of chromatographic methods of analysis.

Thus, the studies carried out show that ethyl alcohol used for the sample preparation of transformer oil contains a large amount of water and associated impurities that negatively affect the liquid-phase extraction process. More promising is the high-boiling aliphatic alcohols, which are characterized by a low content of moisture and associated impurities.

In fig. 3. The dependence of the logarithm of the retention time of ethyl alcohol and ionol on the analysis temperature is shown.

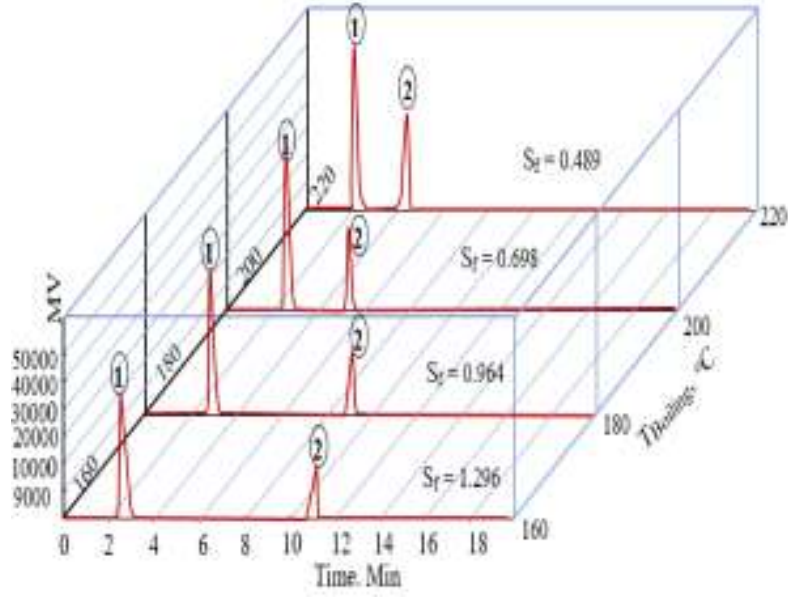

Fig. 3. Chromatogram of the separation of ethyl alcohol and ionol under isothermal conditions at different temperatures $\left(160^{\circ} \mathrm{C}-220^{\circ} \mathrm{C}\right)$ in the coordinates: response of the detector signal, $\mathrm{mV}$ analysis temperature, ${ }^{0} \mathrm{C} .1$ - Ethyl alcohol; 2 Ionol.

Fig. 4 shows dependence of the logarithm of the retention time of n-butanol and ionol on the analysis temperature is shown.

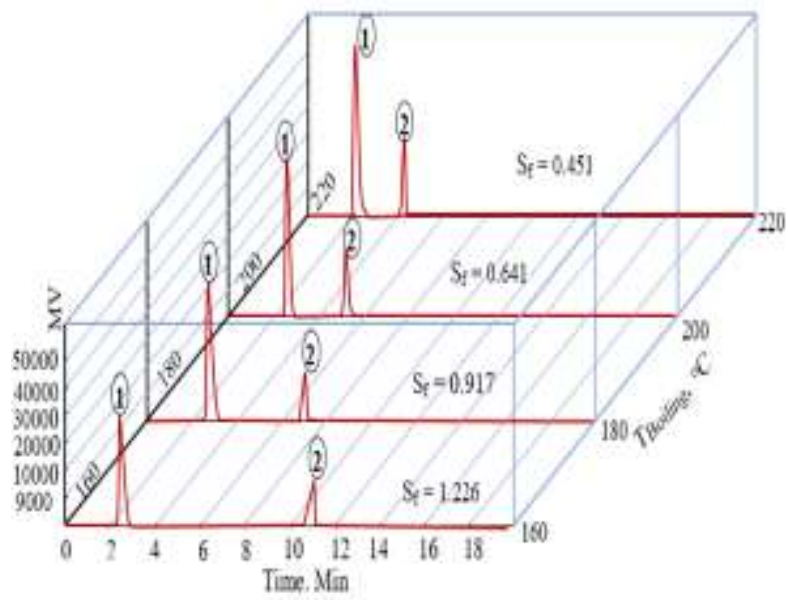

Fig. 4. Chromatogram of the separation of n-butanol and ionol under isothermal conditions at different temperatures $\left(160^{\circ} \mathrm{C}\right.$ $220^{\circ} \mathrm{C}$ ) in the coordinates: response of the detector signal, $\mathrm{mV}$ analysis temperature, ${ }^{0} \mathrm{C} .1-$ n.-Butanol; 2 - Ionol.

Fig 4 shows, in all cases, there is a significant decrease in the retention time of all organic solvents with an increase in temperature in the range from $160^{\circ} \mathrm{C}$ to $220^{\circ} \mathrm{C}$. At the same time, at low temperatures of analysis, the peak of the antioxidant additive is blurred, which is its rather high boiling point. With increasing analysis temperature, the chromatographic peak of the antioxidant additive becomes more symmetric. In this case, the selectivity of the separation of organic solvents and antioxidant additives also depends on the temperature.

\section{Conclusion}

The retention characteristics of aliphatic alcohols used as an organic extractant in the extraction of the antioxidant 
additive "Ionol" from transformer oil were determined by the method of high-performance gas-liquid chromatography using a quartz capillary column with a polar stationary phase. Dependences have been revealed linking the physicochemical properties of aliphatic alcohols and ionol with the conditions of chromatographic analysis. A linear dependence of the relative volume of retention of aliphatic alcohols on the temperature of the chromatographic column was established.

\section{References}

1. R.A. Lipstein, In collection. tr. second all-Union, scientific. technical meeting (M: Chemistry 1968)

2. G.I. Rizvanova, L.G. Gafiyatullin, M.S. Garifullin, et all, Energy problems, 9-10, 4 (2015)

3. P. Zukowski, T. Koltunowicz, K. Kierczynski, J. Subocz, M. Gutten, M. Szrot, M. Sebok, J. Jurcik, IEEE Transactions on Dielectrics and Electrical Insulation, 22, 8 (2015)

4. Tapan Kumar Saha, Prithwiraj Purkait, Transformer Ageing - Monitoring and Estimation Techniques (2017)

5. L. Bartha, G.Y. Deak, J. Hancock, J. Baladincz, J. Auer, G. Kocsis, Lubrication Science, 13, 15 (2001)

6. S. Tenbohlen, S. Koch, et all, Proc. of 42nd CIGRE Session, Paris, A 2, 1 (2008)

7. V. Arakelian, IEEE Electrical Insulation Magazine, 18, 17 (2002)

8. Yang Liua, Vang Lijun, Hu Ende, Huang Jiajia, IEEJ Transformers on Electrical and Elecnronic Engineering, 10, 6 (2015)

9. V. Lopatin, M.D. Noskov, R. Badent, K. Kist, A.I. Schwab, IEEE Transformer on Dielectric and Electrical Insulation, 5, 8 (1998)

10. R. Ocon, R. Montes, et all, Proc. of 45th CIGRE session, Paris, A 2, 1 (2014)

11. Z. Wang, A. Darwin, R. Martin, Proc. of CIGRE colloquium Brugge, A 2, 1 (2007)

12. D. Imamovic, K.X. Lai, et all, Proc. of CIGRE colloquium, Brugge, 16, 7 (2007)

13. M. Martins, G. Augusta, A.R. Gomes, JEFF lec. Mag., 28, 7 (2012)

14. R. Shuangzhan, R. Lisheng, Y. Qinxue, C. Xiaolong, L. Shengtao, IEEE Trans. Dielec. and Elec. Insul., 19, 6 (2012)

15. L.N. Andreev, P.P. Pavlova, S.A. Pinigin, Electronic scientific and practical journal "Modern technique and technology", 3 (2017)

16. A.V. Taneyeva, Vu Ngoc Zan, Nguyen Zui Xing, A.V. Dmitriev, V.A. Novikov, Sorption and chromatographic processes, 19, 5 (2019)

17. A.V. Taneeva, A.V. Dmitrieva, V.F. Novikov, V.K. Ilyin, Analytics and Control, 24, 10 (2020)

18. A. V. Taneeva, V. K. Ilyin, Power engineering: research, equipment, technology , 22, 4 (2020).
19. S.M. Korobeynikov, M.N. Lyutikova, Problems of regional energy, 36, 10 (2018)

20. Nguyen Duy Hung, V.F. Novikov , Power engineering: research, equipment, technology , 22, 5 (2020). 